\title{
SIMULINK Based Model for Determination of Different Design Parameters of a Three Phase Delta Connected Squirrel Cage Induction Motor
}

\author{
Bhaskar Lodh \\ (Department of Electrical Engineering, Bengal Institute of Technology \& Management, West Bengal, India)
}

\begin{abstract}
Electrical Machine Design is a renown discipline of electrical engineering, which can be termed as the physical implementation of theoretical knowledge .A machine is designed considering different aspects likequality and availability of materials, availability of suitable mechanism and skilled labor, cost, durability etc. In this paper, a computer based model (using SIMULINK) is furnished for obtaining the suitable dimensions of a three phase squirrel cage induction motor. The main objective of the work is to determine the dimensions of various parts and components of the motor, specify suitable materials for design and obtain the output parameters. Now-a-days, induction motors have become the workhorse of the industrial sector due to their easy means of construction and maintenance. Therefore, the performance of the machine needs to be specified using computer aided programs. In this paper, the input parameters of the induction motor is so chosen that it will offer a very competitive pricing and good efficiency.
\end{abstract}

Keywords: Electrical Machine Design, End ring, Squirrel cage Motor, SIMULINK

\section{INTRODUCTION}

In practical design of an induction motor, the designer has to follow a number of constraints. Also, the number of input variables is also high. Therefore, manual calculation becomes very much tedious. In order to overcome this, one needs to build a computer aided program or simulation model for determining the parameters of the specific motor. In this paper, a SIMULINK based model is constructed for an induction motor, which will provide high efficiency. Also, the manufacturing cost of the machine will be less and therefore the motor will offer a very competitive pricing. Different parameters of the motor like- rating of the motor (KW/KVA), supply voltage, frequency, type of connection (star/delta), desirable efficiency and power factor, magnetic flux density etc. are specified. Depending on these specified values, the SIMULINK models will generate and display the values of different dimensions of the induction motor. It is desirable to describe clearly the objective of the design to which the model should fulfill. The entire process can be explained by the following flowchart-

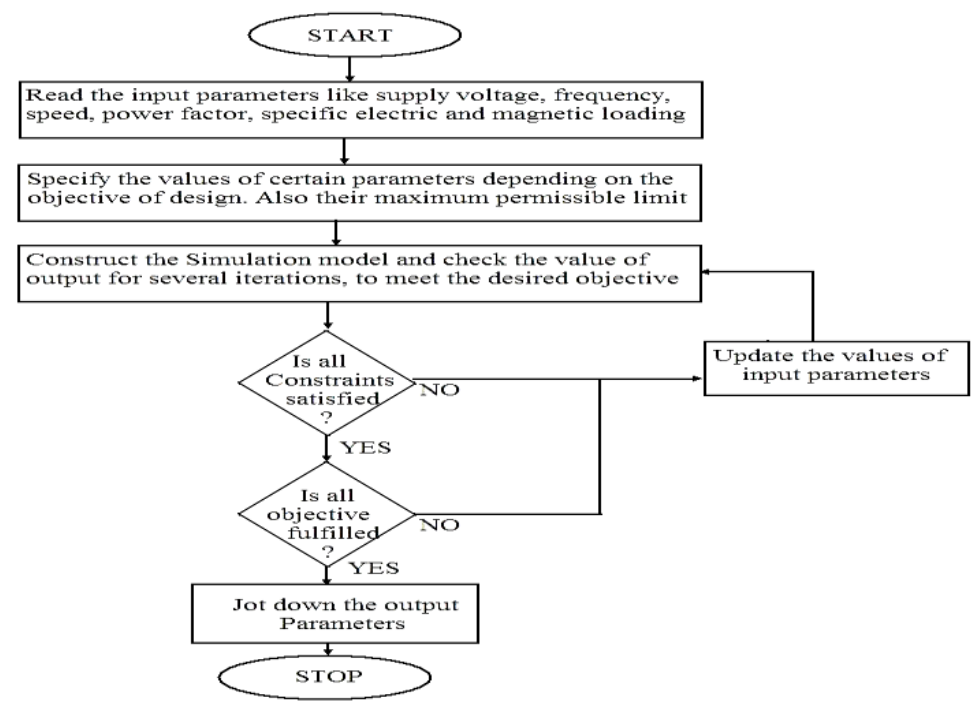

Fig.1. Flow Chart for Constructing a SIMULINK based model for designing three phase induction motor 


\section{INTRODUCTION TO MATLAB-SIMULINK}

In this paper, the software used for constructing the simulation model is MATLAB. It is a very powerful tool for design engineers. It was first introduced in 1970 by a numerical analyst Cleve Moler, who wrote the first version of MATLAB. Since then, it has become successful computational and profit-making software. SIMULINK is a commercial tool furnished by MathWorks Inc. that comes with MATLAB. It is used for modeling and analyzing different types of static and dynamic systems. In this paper, the required simulation model is obtained with the help of different building blocks available in SIMULINK environment.

\section{DESIGN OF MAIN DiMENSIONS}

In this section, diameter (D) and Core length $(\mathrm{L})$ of the stator is determined. The output equation of ac machines is taken as $\mathrm{Q}(\mathrm{KVA})=\mathrm{C}_{0} \mathrm{D}^{2} \mathrm{~L}_{\mathrm{n}}$. Where, $\mathrm{C}_{0}$ is the output coefficient as determined from the SIMULINK diagram shown. In this paper, the power output, power factor, efficiency and speed is specified. For an electrical machine manufacturing company, it's necessary to design an electrical machine that will offer a very competitive pricing. Therefore, it's customary to take higher values of specific electric and magnetic loading (i.e. the values of ac and $\mathrm{B}_{\mathrm{av}}$ ). Here, ampere conductor per meter of the armature periphery (ac) is taken as $21000 \mathrm{~A} / \mathrm{m}$ and average value of flux density in the air gap $\left(\mathrm{B}_{\mathrm{av}}\right)$ is taken as $0.44 \mathrm{~Wb} / \mathrm{m}^{2}$. In order to have a small magnetizing current, flux density should be very low. Otherwise the machine will have a poor power factor and consequently the efficiency of the motor will be less. The corresponding SIMULINK diagram is as follows-
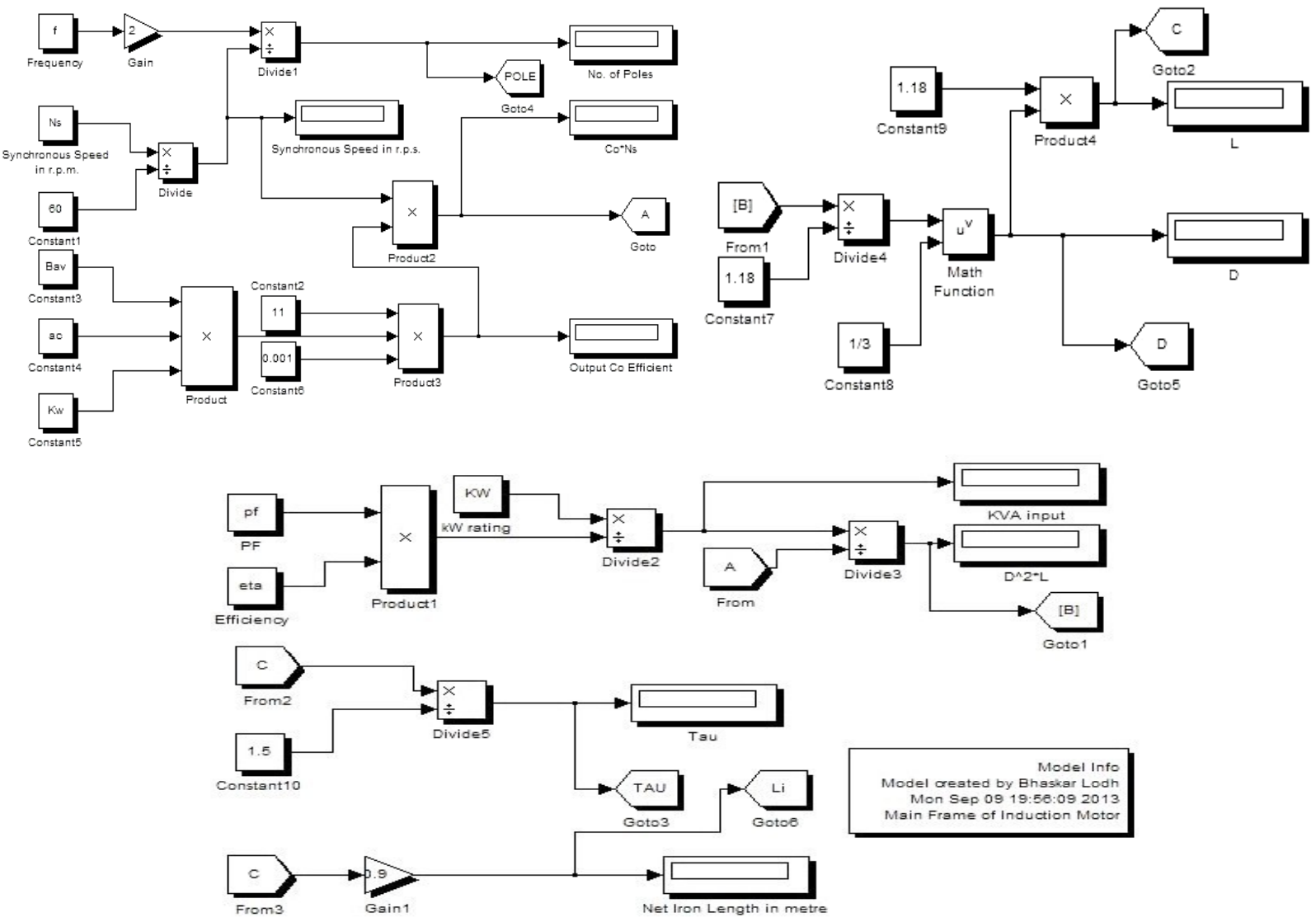

Fig. 2 SIMULINK model for determination of main frame parameters of an Induction motor

In a typical $50 \mathrm{~Hz}$ motor, the value of $B_{\mathrm{av}}$ ranges between $0.3 \mathrm{wb} / \mathrm{m}^{2}$ to $0.6 \mathrm{wb} / \mathrm{m}^{2}$ and ac ranges between 5000 to $45000 \mathrm{~A} / \mathrm{m}$ depending upon the type and application of the machine. In this paper, the taken value of $\mathrm{B}_{\mathrm{av}}$ indicates that the machine will be capable of providing a good overload facility and can be applied in cranes, rolling mills etc. The ratio of Core length to pole pitch (pole pitch is abbreviated as "TAU" in SIMULINK model) i.e. $\frac{L}{\tau}$ differs in different machines according to their design specification.

In this paper the value of $\frac{L}{\tau}$ is taken as 1.5 which is a suitable value taken for minimum cost and good efficiency. In order to attain a good power factor and good overall design of the motor, the value should lie between 1.0 to 1.25 . The peripheral velocity of the motor is expressed in terms of r.p.s. For a normal construction, the peripheral velocity should not exceed the value 30 r.p.s. 


\section{DESIGN OF STATOR}

The stator is the stationary part of the motor, which consists of the outer cylindrical frame of the motor or yoke, which is made either of welded sheet steel, cast iron or cast aluminum alloy. Stator is made of a steel frame which encloses a hollow, cylindrical core fabricated of thin laminations of silicon steel to lessen hysteresis and eddy current losses. A number of evenly spaced slots are provided on the inner edge of the laminations. It forms a balanced star or delta connected circuit. For a typical 3 phase $50 \mathrm{~Hz}$ motor, rotor is separated from the stator by a small air-gap which ranges from $0.4 \mathrm{~mm}$ to $4 \mathrm{~mm}$, depending on the power of the motor. In this paper, the machine is designed for delta connection with a star-delta starter. The stator will be designed with a single layer mush winding where the coil span should not be an even integer. When 3-phase supply is given to the stator winding, a rotating magnetic field is produced which induces currents in the rotor by electromagnetic induction. No. of stator winding turns per phase is calculated as $T_{s}=\frac{E_{s}}{4.44 K_{w s} \varphi_{m}}$, where $E_{s}=$ Applied ac voltage, $K_{w s}=$ Stator winding factor and $\varphi_{m}=$ Maximum flux per pole as calculated from the SIMULINK diagram.

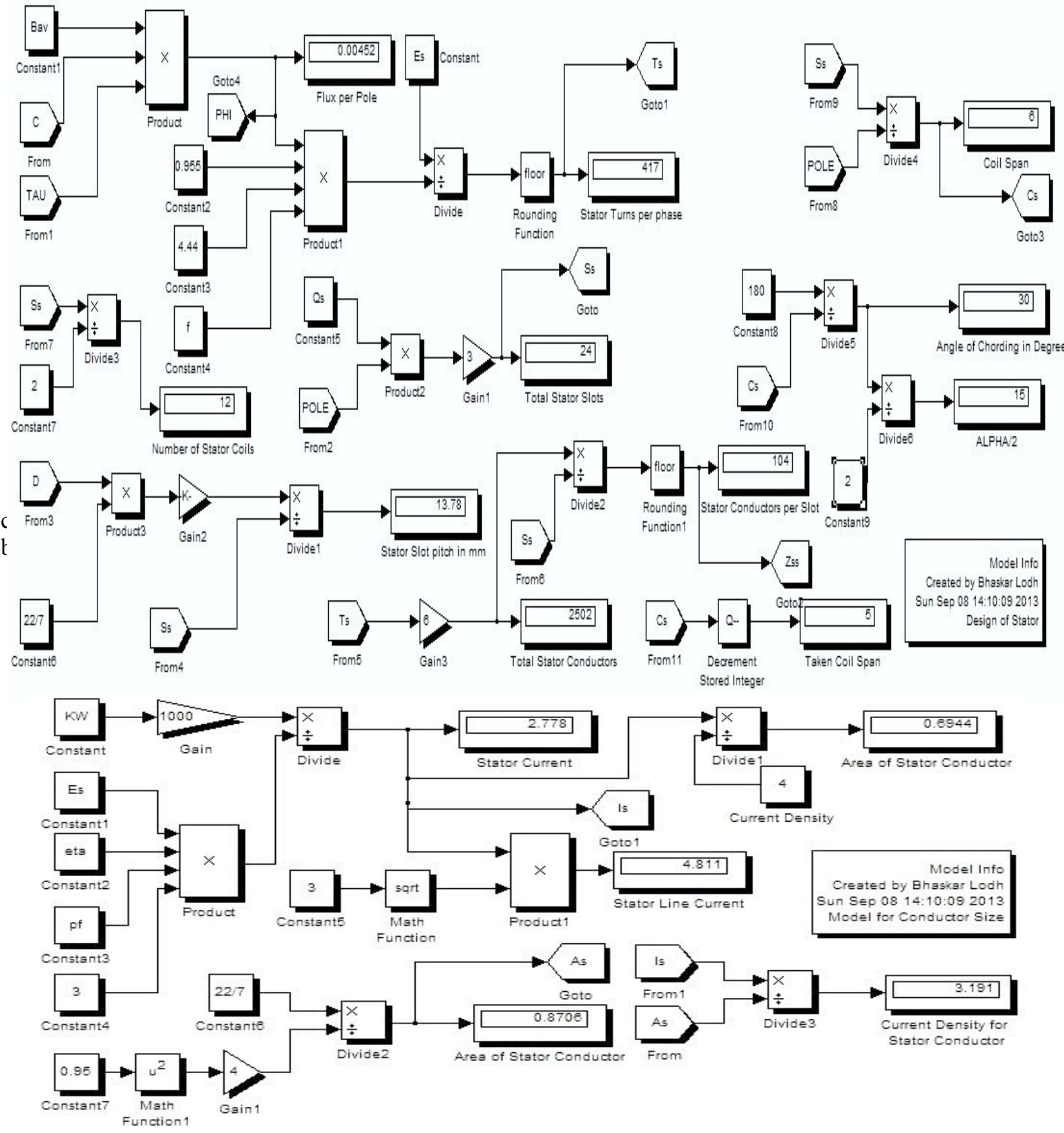

Fig. 4 SIMULINK model for determination of stator conductor size of an Induction motor 


\section{DETERMINATION OF SLOT DIMENSION}

In this section a SIMULINK model is proposed to obtain different parameters of stator slot. For a double lap winding, number of stator slot is calculated as, $S_{s}=$ Number of phases $(\mathrm{M}) \times$ Number of slots $/$ pole/phase $(\mathrm{g}) \times$ Number of poles $(\mathrm{P})$. The shape of the slot of the motor has a great impact on the performance of the motor. The slots may be chosen as completely open or semi-closed. However, the later one is preferred for a three phase induction motor because, it will provide a low magnetizing current as the gap contraction factor is less. Also it will have a quieter operation as compared to the open slots. The SIMULINK diagram is as follows-

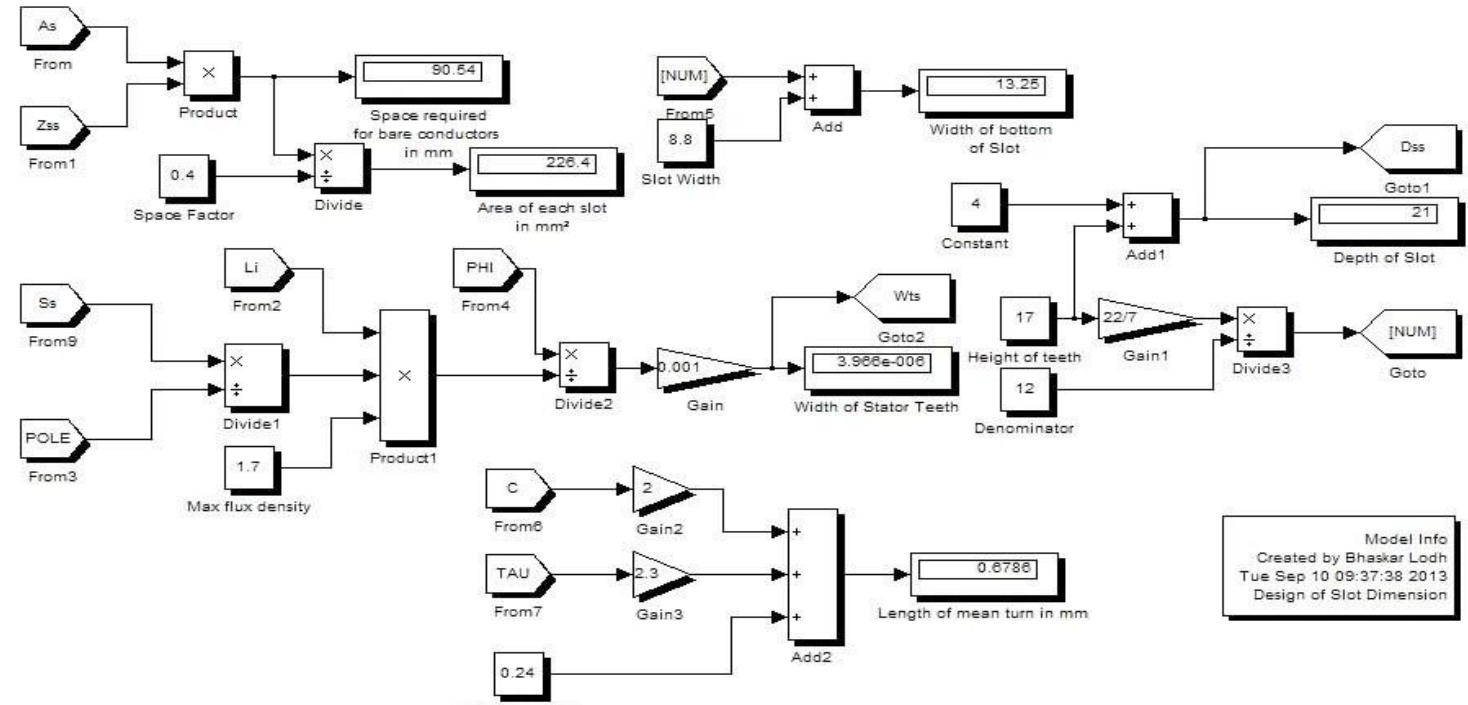

Fig. 5 SIMULINK model for determination of stator slot dimension of an Induction motor

VII. DETERMination OF STATOR CORE AND TEETH Dimension

It is preferred not to have a high value of flux density in the teeth as it will increase iron loss and magnetizing mmf. Therefore the value is taken as low as $1.7 \mathrm{wb} / \mathrm{m}^{2}$. However, in the stator core, value of flux density lies between 1.2 to $1.4 \mathrm{wb} / \mathrm{m}^{2}$. The value of flux density in the stator core will be half the value of flux pole.

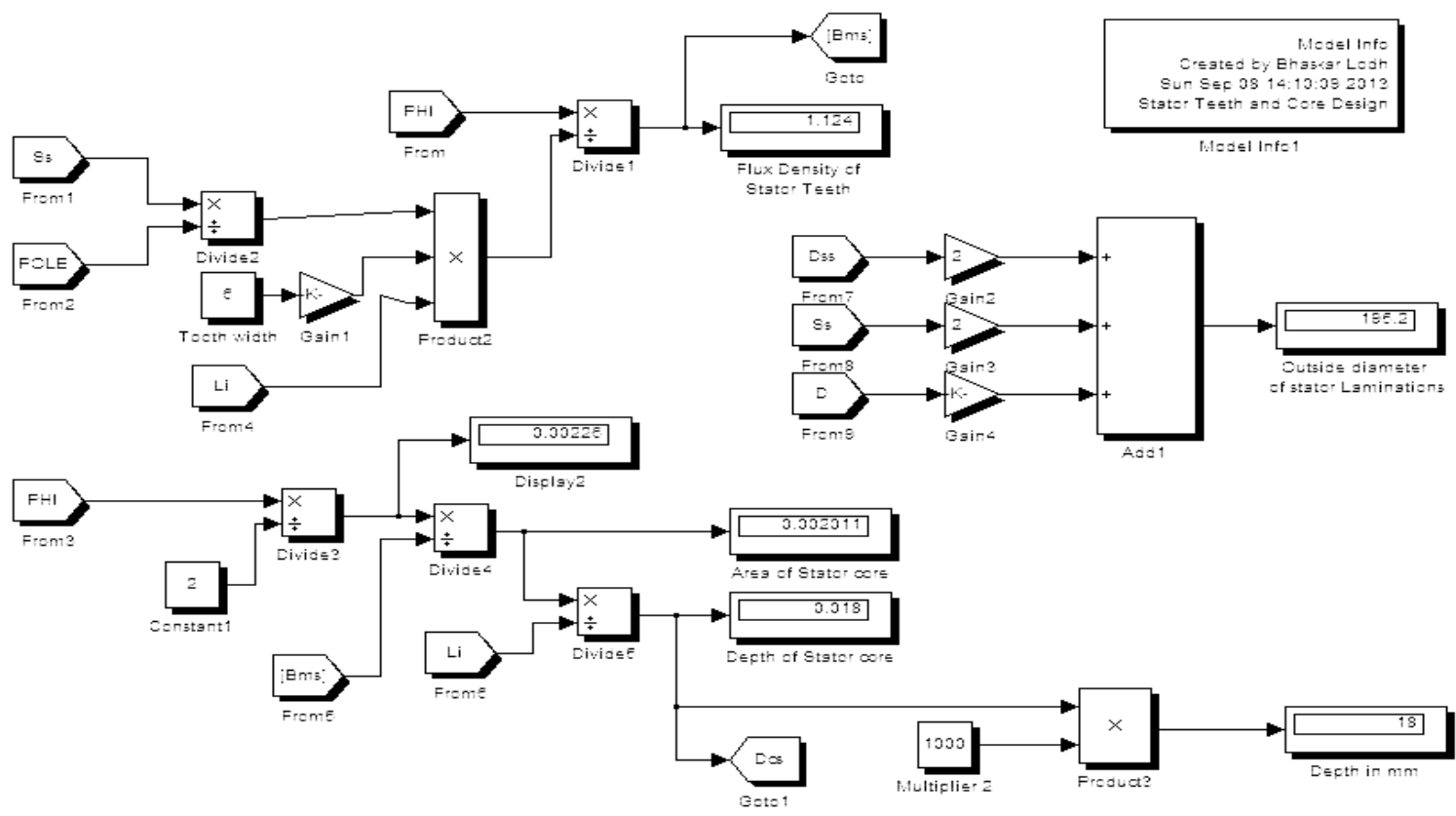

Fig. 6 SIMULINK model for determination of dimension of stator teeth of an Induction motor 


\section{DETERMINATION OF AIR GAP LENGTH}

Air gap length is an important factor to be considered while designing an induction motor. The magnetizing current drawn by the machine solely depends on the length of the air gap. However, with the increase of air gap length, the overload capacity of the induction motor increases. Also, the tooth pulsation loss is inversely proportional to length of air gap. Increasing the air gap length will also decrease the noise caused by the machine and will facilitate better provision of cooling. The length of air gap is determined using the following SIMULINK diagram-

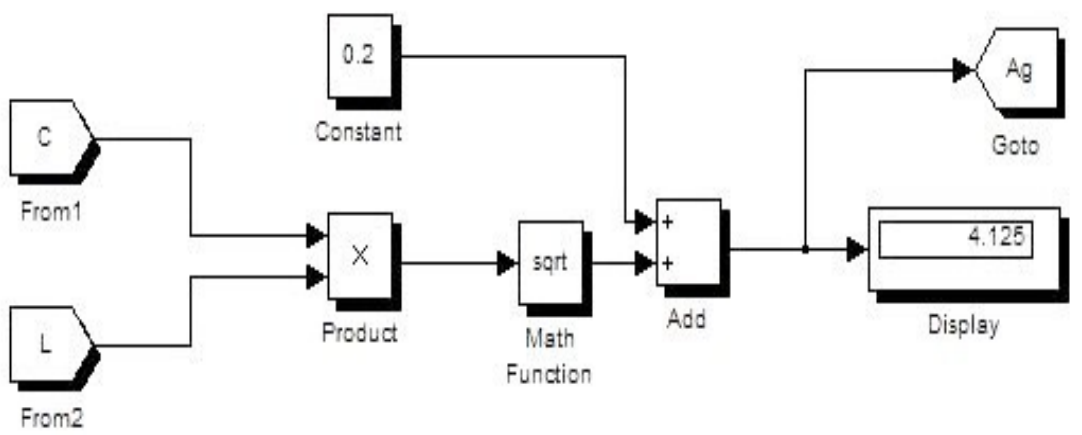

Fig. 7 SIMULINK model for determination of air gap length of an Induction motor

\section{DESIGN OF ROTOR}

The rotor, which is mounted on a shaft, is a hollow laminated cylindrical structure having slots (for housing rotor conductors) on its outer periphery. Rotor windings (conductors) may be one of the following two types: Squirrel cage or Slip ring type. In this paper, the design for a squirrel cage structure is shown. This structure is preferred in industries because it provides a constant speed operation. Here the most important thing is to determine the number of slots to be used in the rotor. Also, the rotor bar current is an important factor that we have to count. To determine the different parameters of the rotor, following SIMULINK model will be used-

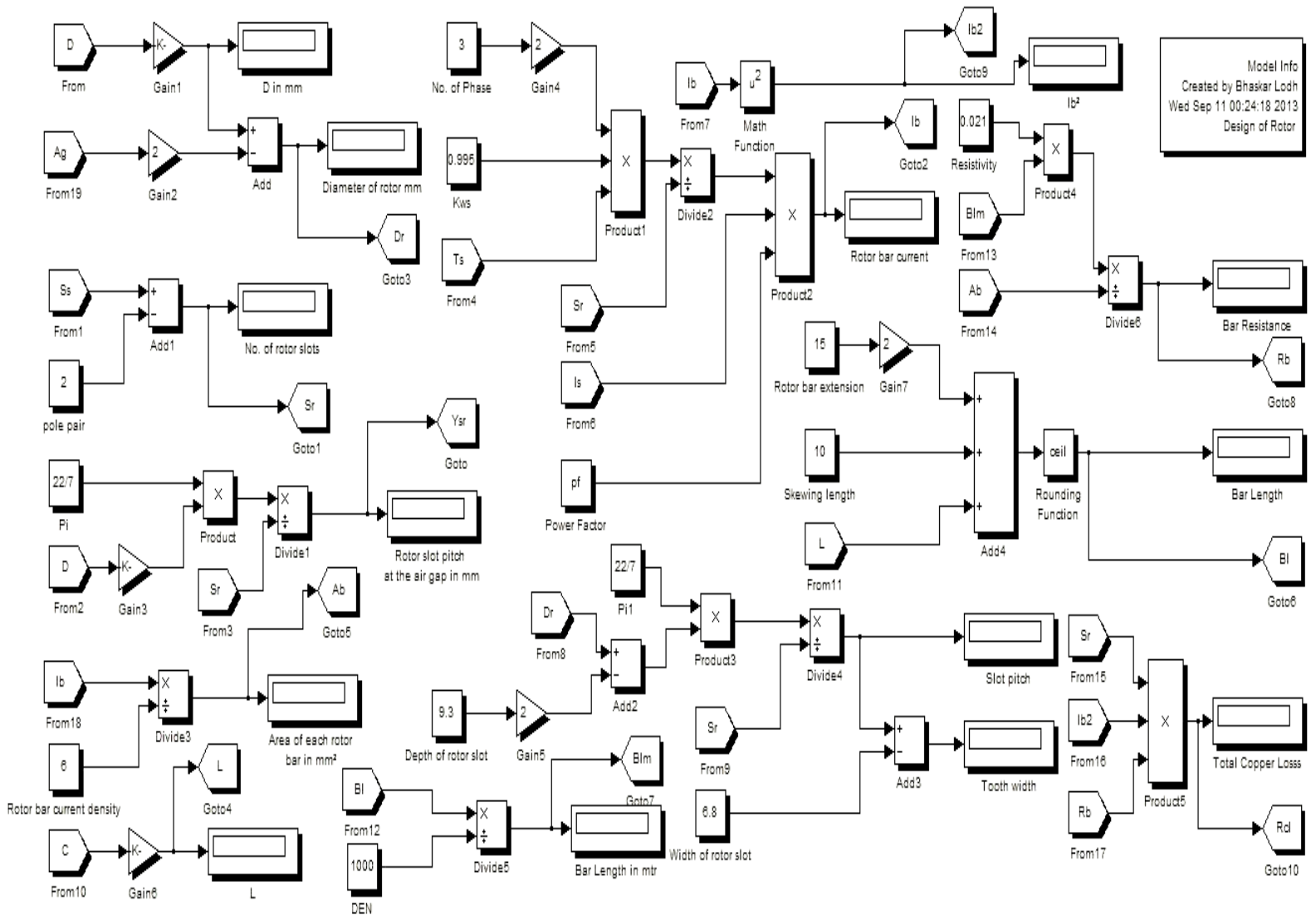

Fig. 8 SIMULINK model for determination of rotor parameters of an Induction motor 


\section{DESIGN OF Rotor CORE AND TeETH}

Here, the depth of rotor core is taken same as that of stator. Some parameters like- diameter of the rotor core, total length of rotor laminations, rotor core area etc. needs to be specified. The corresponding SIMULINK diagram is as follows-

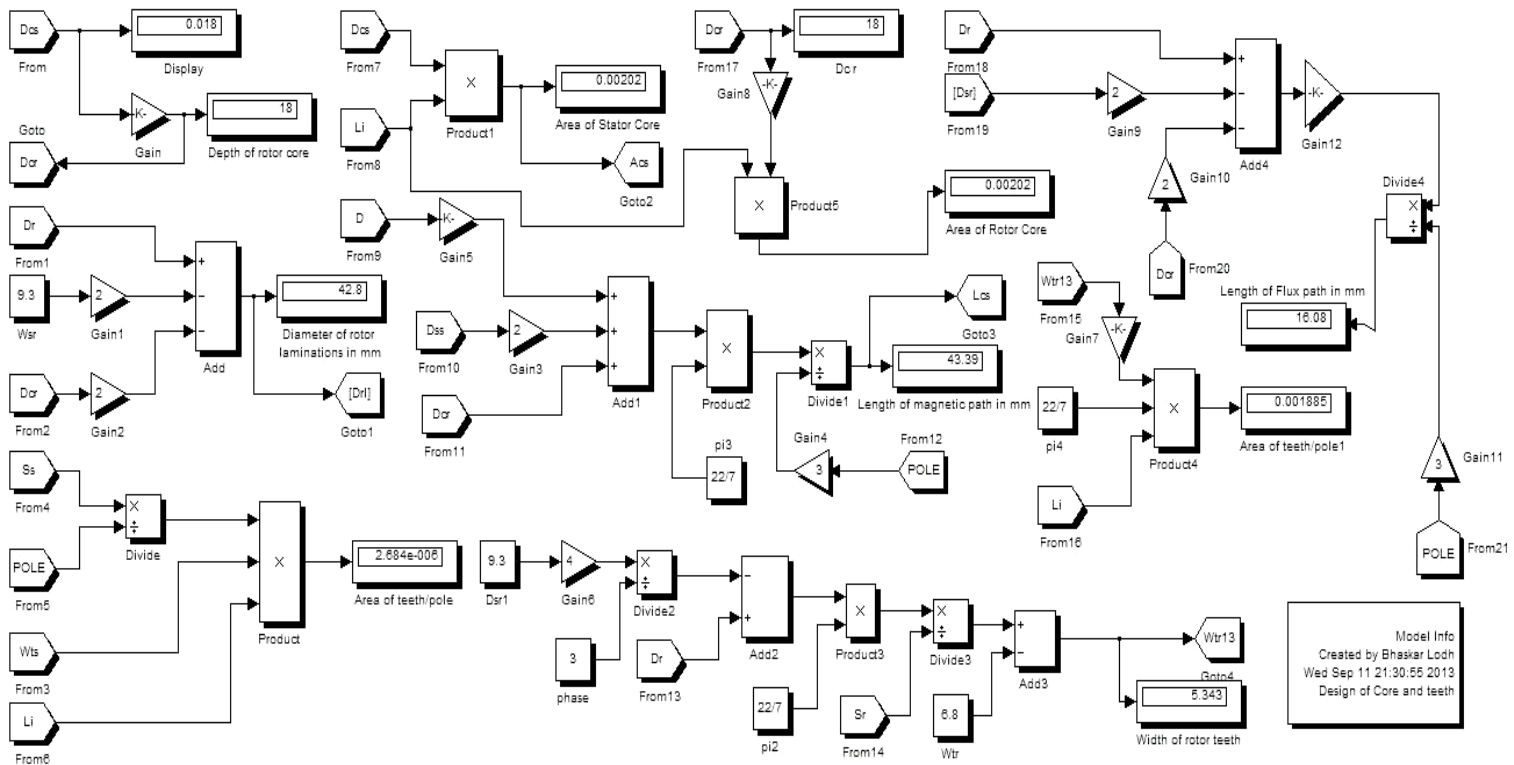

Fig. 9 SIMULINK model for determination of rotor core and teeth dimensions an Induction motor

\section{DESIGN OF END RING AND DETERMINATION OF COPPER LOSS}

The rotor bars of a squirrel cage induction motor always remain short circuited by means of End rings. These are mainly fabricated from copper and brazed on bars. In the following SIMULINK model, effective dc resistance of the End ring is calculated. While designing a motor, it is usually a good practice to neglect the reactance of the end ring, and represent the impedance of the ring only in terms of its resistance. The model also determines the total copper loss and running slip of the induction motor.

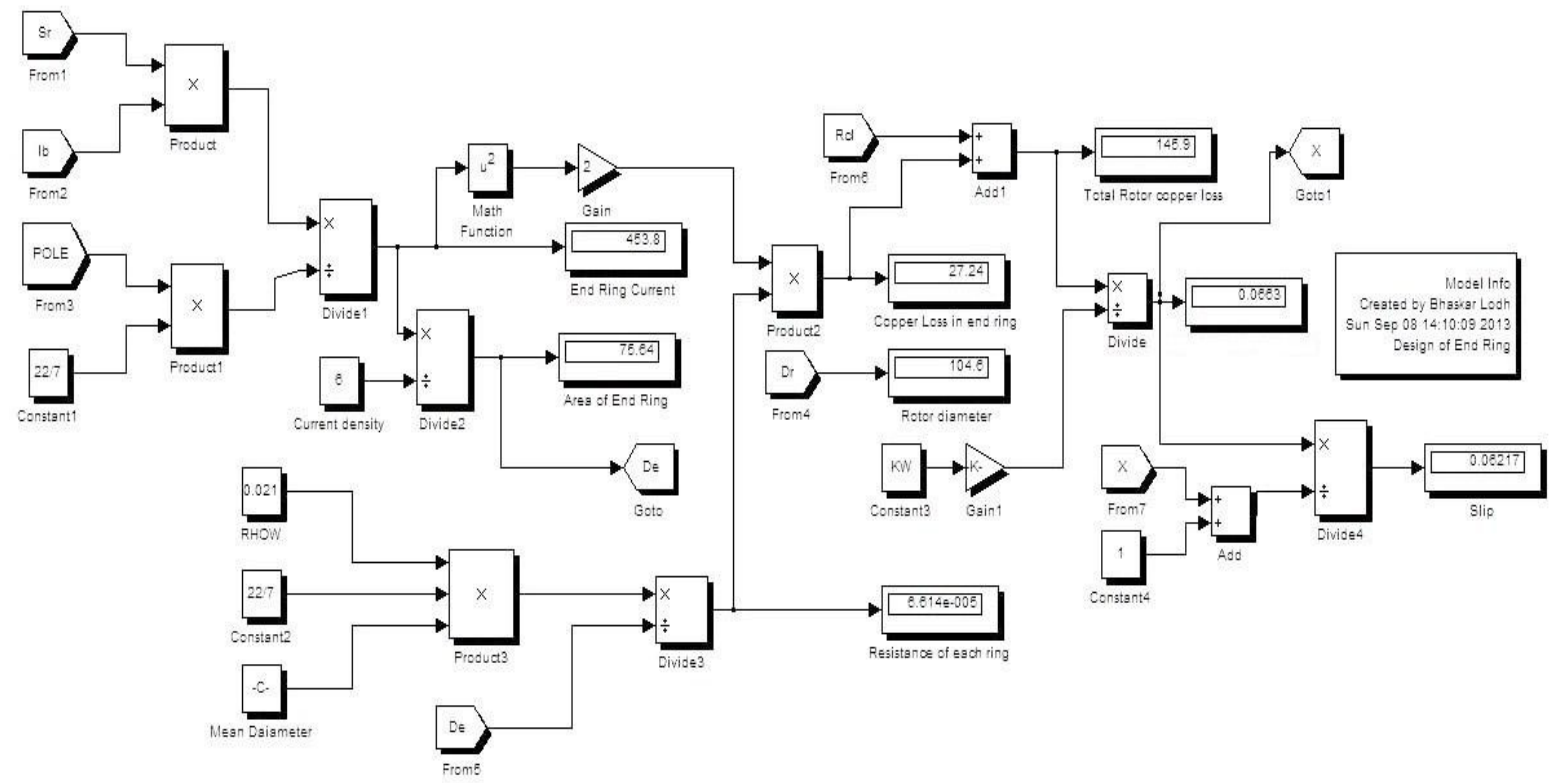

Fig. 10 SIMULINK model for determination of End ring dimension and Copper Loss of an Induction motor 


\section{TEST CASE}

Following input parameters are entered in MATLAB command window. Based on these parameters all the dimensions of the machine are displayed in the corresponding SIMULINK models-

TABLE 1: Input to MATLAB

\begin{tabular}{|c|c|c|}
\hline Name & Nomenclature & Value \\
\hline Synchronous Speed & $\mathrm{N}_{\mathrm{s}}$ & $1500 \mathrm{r} . \mathrm{p} . \mathrm{m}$. \\
\hline Supply Frequency & $\mathrm{f}$ & $50 \mathrm{~Hz}$ \\
\hline Specific magnetic loading & $\mathrm{B}_{\mathrm{av}}$ & $0.44 \mathrm{~Wb} / \mathrm{m}^{2}$ \\
\hline Specific electric loading & $\mathrm{ac}$ & $21000 \mathrm{~A} / \mathrm{m}$ \\
\hline Rated output of the Motor & $\mathrm{Q}(\mathrm{KW})$ & $2.5 \mathrm{KW}$ \\
\hline Winding factor & $\mathrm{Kw}$ & 0.955 \\
\hline Efficiency & $\eta(\mathrm{eta})$ & 0.86 \\
\hline Power Factor & $\mathrm{pf}$ & 0.86 \\
\hline Stator slots per pole/ phase & $\mathrm{Q}_{\mathrm{s}}$ & 2 \\
\hline Supply Voltage & $\mathrm{E}_{\mathrm{s}}$ & $440 \mathrm{Volt}$ \\
\hline
\end{tabular}

\section{RESUlt OF Simulation}

Based on the input parameters the, the calculated dimensions of the machine shown by SIMULINK models are as shown below-

1. Number of poles $=4$

2. Synchronous speed in r.p.s. $=25$

3. Output coefficient $\left(\mathrm{C}_{\mathrm{o}}\right)=97.07$

4. Stator bore diameter $(\mathrm{D})=0.1247 \mathrm{~m}$

5. Stator Core length $(\mathrm{L})=0.1247 \mathrm{~m}$

6. Pole pitch $(\tau)=0.08314 \mathrm{~m}$

7. Net iron length $\left(L_{i}\right)=0.1122 \mathrm{~m}$

8. Flux per pole $=0.0045 \mathrm{~Wb}$

9. Stator turns per phase $=454$

10. Number of stator slots $=24$

11. Stator slot pitch $=13.84 \mathrm{~mm}$

12. Number of stator coils $=12$

13. Coil $\mathrm{span}=6$

14. Angle of Chording $(\alpha)=30^{\circ}$

15. Total stator conductor $=2724$

16. Total stator conductor per slot $=113$

17. Taken value of coil $\mathrm{span}=5$

18. Stator current per phase $=2.561 \mathrm{~A}$

19. Area of stator conductor $=0.8706 \mathrm{~mm}^{2}$

20. Stator line current $=4.435 \mathrm{~A}$

21. Taken value of area of stator conductors $=0.6402 \mathrm{~mm}^{2}$

22. Current density of stator conductors $=2.941 \mathrm{~A} / \mathrm{mm}^{2}$

23. Space required for bare conductors $=98.38 \mathrm{~mm}^{2}$

24. Area of each slot $=245.9 \mathrm{~mm}^{2}$

25. Width of bottom of slot $=13.25 \mathrm{~mm}$

26. Depth of slot $=21 \mathrm{~mm}$

27. Width of stator teeth $=3.95 \times 10^{-6} \mathrm{~mm}$

28. Length of mean turn $=0.6806 \mathrm{~mm}$

29. Flux density of stator teeth $=1.129 \mathrm{~Wb} / \mathrm{m}^{2}$

30. Outside diameter of stator laminations $=195.7 \mathrm{~mm}$

31. Area of stator core $=0.00202 \mathrm{~m}^{2}$

32. Depth of stator core $=0.018 \mathrm{~mm}$

33. Diameter of rotor $=97.4 \mathrm{~mm}$

34. Number of rotor slots $=22$

35. Area of each bar $=45.22 \mathrm{~mm}^{2}$

36. Rotor slot pitch in air gap $=15.1 \mathrm{~mm}$

37. Rotor bar current $=271.3 \mathrm{~A}$

38. Rotor bar resistance $=7.663 \times 10^{-5} \mathrm{ohm}$

39. Rotor bar length $=165 \mathrm{~mm}$ 
40. Rotor slot pitch $=11.26 \mathrm{~mm}$

41. Rotor tooth width $=4.467 \mathrm{~mm}$

42. Rotor copper loss $=124.12 \mathrm{~W}$

43. End ring current $=474.8 \mathrm{~A}$

44. Area of end ring $=79.13 \mathrm{~mm}^{2}$

45. Resistance of each ring $=6.322 \times 10^{-5} \mathrm{ohm}$

46. Copper loss in end ring $=28.5 \mathrm{~W}$

47. Depth of rotor core $=18 \mathrm{~mm}$

48. Diameter of rotor laminations $=42.8 \mathrm{~mm}$

49. Width of rotor teeth $=5.342 \mathrm{~mm}$

50. Slip of the motor $=0.05753(\cong 5.8 \%)$

\section{CONCLUSION}

Different dimensions of the three phase induction motor are obtained from the SIMULINK diagrams. The "slip" of the motor came out as $5.8 \%$ which is an acceptable value. In this paper, an attempt has been made to develop a model for analysis of three phase induction motor. The developed models has been tested with the above mentioned test specifications. Here, all possible testing were carried out on and errors are minimized for successful operation of the software. Different examples are considered to study the performance of the developed SIMULINK model. Test results are obtained and compared with actual result.

\section{References}

[1] I.J. Nagrath, D.P. Kothari, Electrical Machines (New Delhi, Tata McGraw-Hill Publishing company Limited, 2003)

[2] The MathWorks, Inc, Simulink- Dynamic System Simulation for Matlab (Natick, M A, USA, The MathWorks, Inc, 2000)

[3] A.K. Sawhney, A Course in Electrical Machine Design (Delhi, Dhanpat Rai \& Co,2003)

[4] K.M. Vishnu Murthy, Computer-Aided Design of Electrical machines (Hyderabad, B.S. Publications, 2008)

[5] A.K. Tyagi, MATLAB and Simulink for Engineers (New Delhi, Oxford University Press, 2012) 